\title{
The Diagnosis and Treatment of Autoimmune Blistering Skin Diseases
}

\author{
Enno Schmidt, Detlef Zillikens
}

\begin{abstract}
SUMMARY
Background: Autoimmune blistering skin diseases are a heterogeneous group of disorders associated with autoantibodies that are directed against desmosomal structural proteins (in pemphigus diseases) or hemidesmosomal ones (in pemphigoid diseases and epidermolysis bullosa acquisita), or else against epidermal/ tissue transglutaminases (in dermatitis herpetiformis). Knowledge of the clinical presentation of these disorders and of the relevant diagnostic procedures is important not just for dermatologists, but also for general practitioners, ophthalmologists, ENT specialists, dentists, gynecologists, and pediatricians.
\end{abstract}

Methods: The literature on the subject was selectively reviewed. There are no existing guidelines available in Germany.

Results: The recently developed sensitive and specific assays for circulating autoantibodies in these diseases now enable a serological diagnosis in about $90 \%$ of cases. The incidence of autoimmune blistering skin diseases in Germany has doubled in the last 10 years, to a current figure of about 25 new cases per million persons per year, because of improved diagnostic techniques as well as the aging of the population. Accurate and specific diagnosis is the prerequisite for reliable prognostication and appropriate treatment. For severe and intractable cases, more effective treatments have recently become available, including immunoadsorption, high-dose intravenous immunoglobulin, the anti-CD20 antibody rituximab, and combinations of the above.

Conclusion: The diagnostic assessment of autoimmune blistering skin diseases can be expected to improve in the near future as new serological testing systems are developed that employ recombinant forms of the target antigens. The treatments currently in use still need to be validated by prospective, controlled trials.

\section{$\checkmark$ Cite this as:}

Schmidt E, Zillikens D: The diagnosis and treatment of autoimmune blistering skin diseases. Dtsch Arztebl Int 2011; 108(23): 399-405. DOI: 10.3238/arztebl.2011.0399

Exzellenzzentrum für Entzündungsmedizin, Klinik für Dermatologie, Allergologie und Venerologie, Universität zu Lübeck: Prof Dr. med. Dr. rer. nat. Schmidt

Klinik für Dermatologie, Allergologie und Venerologie, Universität zu Lübeck: Prof. Dr. med. Zillikens

\begin{abstract}
1 utoimmune blistering skin diseases are a heterogeneous group of conditions clinically characterized by blisters and erosions on the skin and close-tosurface mucous membranes. In pemphigus diseases, the autoantibodies are directed against desmosomal proteins, and cell contact within the epidermis is lost. In subepidermal autoimmune blistering diseases, the antibodies are directed against hemidesmosomal structural proteins, and the result is cleavage between the epidermis and the dermis (Table 1, Figure 1). In this article, we will describe the clinical course of these diseases, current epidemiological trends, recently developed diagnostic tests, and treatment options. As there are no current guidelines on the subject in Germany, this article is based on a review of the pertinent literature.
\end{abstract}

\section{Clinical features}

In pemphigus, since cleavage occurs within the epidermis, blisters have a relatively thin roof and are loose and fragile; thus, skin erosion, rather than blistering, tends to be the predominant finding in pemphigus vulgaris and the nearly exclusive finding in pemphigus foliaceus (Figure 2b). The main difference between these two conditions, however, lies in the degree of involvement of the mucous membranes. In pemphigus vulgaris, the mucous membranes are always involved (Figure 2a), while the skin may or may not be affected; in pemphigus foliaceus, the mucous membranes always remain normal (e1). Paraneoplastic pemphigus is characterized by the associated neoplasia, marked stomatitis, and polymorphic skin changes: not just blisters and erosions, but also lichen ruber-like plaques and pustules (e2-e4). IgA pemphigus, the rarest type, is typically associated with pustule formation.

In subepidermal blistering diseases, cleavage occurs between the epidermis and the dermis; thus, the blisters have a thicker roof than the blisters of pemphigus, and are usually tense (Figures $2 c$ and $2 d$ ). Bullous pemphigoid (BP) is almost always associated with severe itch and is a disease of the elderly, with a mean age of onset of 76 years (e5). Pemphigoid gestationis manifests itself during pregnancy or in the immediate postpartal period and is also associated with severe itch. Pemphigoid gestationis usually presents without blisters but rather with eczematous, urticarial, or papular skin changes. Linear IgA dermatosis is the most common autoimmune blistering disease in children. It can clinically resemble BP (anti-laminin- $\gamma 1$ pemphigoid, also 
TABLE 1

Tests to establish the diagnosis of autoimmune blistering skin diseases through the use of recombinant or cellular target antigens

\begin{tabular}{|c|c|c|}
\hline Disease & $\begin{array}{l}\text { Commercially available } \\
\text { ELISA }\end{array}$ & $\begin{array}{l}\text { Western blot. commer- } \\
\text { cially unavailable ELISA }\end{array}$ \\
\hline \multicolumn{3}{|l|}{ Pemphigus } \\
\hline Pemphigus vulgaris & $\begin{array}{l}\text { Desmoglein } 3 \\
\text { Desmoglein } 1\end{array}$ & - \\
\hline Pemphigus foliaceus & Desmoglein 1 & - \\
\hline Paraneoplastic pemphigus & $\begin{array}{l}\text { Envoplakin } \\
\text { Desmoglein } 1 \text { and 3, B230 }\end{array}$ & $\begin{array}{l}\text { Periplakin, desmoplakin I } \\
\text { and II, a2-macroglobulin- } \\
\text { like1, plectin }\end{array}$ \\
\hline \multicolumn{3}{|c|}{ Subepidermal autoimmune blistering skin diseases } \\
\hline Bullous pemphigoid & BP180 NC16A, BP230 & - \\
\hline Pemphigoid gestationis & BP180 NC16A, BP230 & - \\
\hline Linear IgA dermatosis & - & $\begin{array}{l}\text { Soluble ectodomain of } \\
\text { BP180 (LAD-1) }\end{array}$ \\
\hline $\begin{array}{l}\text { Mucous membrane } \\
\text { pemphigoid }\end{array}$ & BP180 NC16A, BP230 & $\begin{array}{l}\text { C-terminus of BP180, } \\
\text { laminin } 332 \text {, a6 } \beta 4 \text {-integrin }\end{array}$ \\
\hline $\begin{array}{l}\text { Lichen planus } \\
\text { pemphigoides }\end{array}$ & BP180 NC16A, BP230 & - \\
\hline $\begin{array}{l}\text { Anti-Laminin } \gamma 1 \text { / p200 } \\
\text { Pemphigoid }\end{array}$ & - & Laminin $\gamma 1$ \\
\hline $\begin{array}{l}\text { Epidermolysis bullosa } \\
\text { acquisita }\end{array}$ & - & Type VII collagen \\
\hline $\begin{array}{l}\text { Dermatitis } \\
\text { herpetiformis }\end{array}$ & $\begin{array}{l}\text { Epidermal/tissue } \\
\text { transglutaminase }\end{array}$ & - \\
\hline
\end{tabular}

The main target antigens are indicated in boldface type.

known as anti-p200 pemphigoid, can do this as well); in linear IgA dermatosis, however, the tense blisters are frequently seen in a ring-like arrangement. Mucous membrane pemphigoid is characterized by the predominant involvement of the mucous membranes that are near the surface of the body. Ocular involvement carries the risk of blindness. Epidermolysis bullosa acquisita has two clinical variants: an inflammatory variant resembling BP or mucous membrane pemphigoid, and a mechano-bullous variant associated with blisters and erosions at mechanically exposed sites which usually heal with scars or milia. Patients with dermatitis herpetiformis develop markedly pruritic, often excoriated papules, mainly on the extensor surfaces of the limbs, on the scalp, and on the buttocks. Blisters, on the other hand, are rare.

\section{Incidence}

In Germany, there are an estimated 2000 new cases of autoimmune blistering skin diseases per year, with an overall prevalence of about 12000 cases. The incidence of pemphigus in Central Europe is one to two cases per million persons per year, and $80 \%$ of pemphigus patients have pemphigus vulgaris (e6). $\mathrm{BP}$ is the most common type of subepidermal autoimmune blistering skin disease in Central Europe, with an incidence of about 13 cases per million persons per year; the next most common types are mucous membrane pemphigoid and pemphigoid gestationis (1, e7-e10). The incidence of BP in Great Britain was recently reported to be twice as high as this, though there is reason to suspect that this estimate is too high as a result of the particular epidemiological methods by which it was derived (1). Interestingly, the incidence of BP in Germany has nearly doubled in the last ten years (e7, e8). This is probably due to improved diagnosis as well as to the aging of the population. BP is the only autoimmune disease whose incidence increases with advancing age: among persons over age 80 , its incidence is between 150 and 180 per million persons per year (e9, e11). BP is often preceded by a non-blistering premonitory stage with marked itch and should thus always be excluded in an elderly patient presenting with pruritus; currently, this can usually be done serologically.

\section{Diagnostic evaluation \\ Direct immunofluorescence}

The current gold standard of diagnostic testing for autoimmune blistering skin diseases is direct immunofluorescence (IF) microscopy to demonstrate tissuebound autoantibodies and/or of C3 in the patient's skin or mucous membranes (e12). By direct IF microscopy pemphigus and subepidermal blistering diseases can be differentiated

\section{Serological tests}

Indirect IF microscopy of the patient's serum can be used as a screening test for circulating antibodies. Indirect IF microscopy on monkey or guinea pig esophagus has become an established mode of testing for serum antibody in pemphigus (Figure $3 a$ ); for the subepidermal autoimmune blistering diseases, the preferred substrate is normal human skin that has been split with $1 \mathrm{M}$ sodium chloride solution (Figures $3 b$ and $3 c$ ) (e13). In patients with dermatitis herpetiformis, IgA reactivity against the endomysium can be visualized on monkey esophagus (e14). Definitive diagnostic testing follows, with the aid of various ELISA or Western blot studies involving the relevant target antigens (Table 1). Some of these ELISAs are commercially available (Table 1). Nowadays, these tests usually suffice to establish the diagnosis by serology in conjunction with a compatible clinical picture.

For the diagnosis of pemphigus vulgaris and pemphigus foliaceus, sensitive and specific commercial ELISAs for the detection of antibodies against desmoglein 1 and 3 are available (2, e15, e16). The great majority of patients with paraneoplastic pemphigus show reactivity to envoplakin and/or periplakin (e17-e19), which can be detected by immunoblotting with extract of cultured human keratinocytes, or else in a recently developed ELISA employing a recombinant envoplakin N-terminal fragment (e19). In BP, the $16^{\text {th }}$ noncollagenous domain (NC16A) is the immunodominant region of $\mathrm{BP} 180$; $\mathrm{IgG}$ autoantibodies against it are 


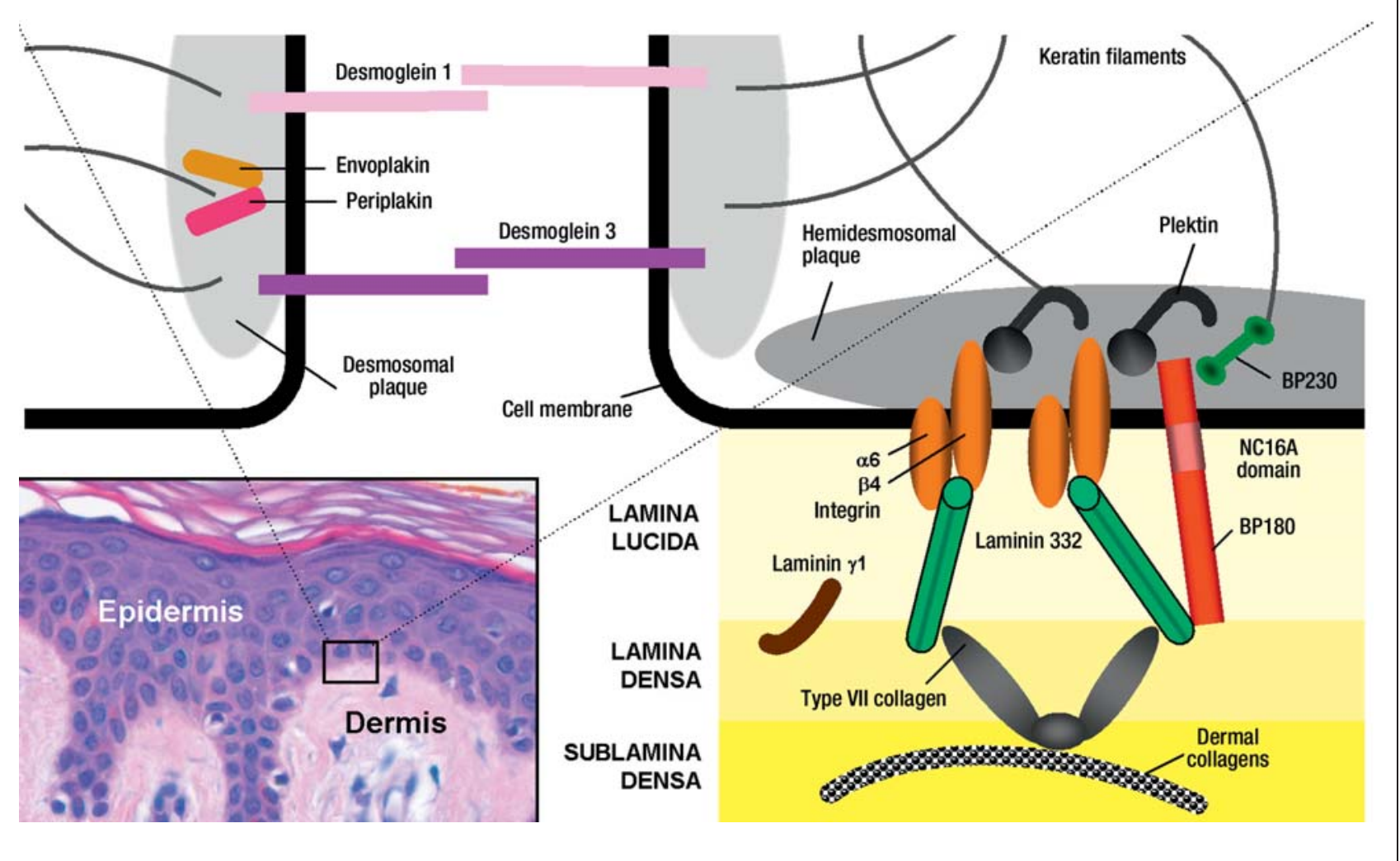

A schematic view of desmosomal and hemidesmosomal target antigens in autoimmune blistering diseases, and the interactions between them. In the histological section of normal skin at bottom left, one sees the epidermis, the dermis, and the dermo-epidermal junctional, also called the basal membrane, zone, which connects the epidermis to the dermis. Two neighboring basal keratinocytes are shown schematically. Pemphigus diseases are histologically characterized by intraepidermal cleft formation; their target antigens are desmosomal structural proteins by means of which neighboring keratinocytes adhere to each other. The desmosomal target antigens of the pemphigus diseases include desmosomal plaque proteins (envoplakin, desmoplakin, periplakin) and transmembrane proteins of the cadherin group (desmoglein 1 and 3, desmocollin 1) whose extracellular portions mediate the adhesion of neighboring keratinocytes (left side of diagram). Hemidesmosomal proteins anchor the epidermis to the dermis and are the target antigens in subepidermal autoimmune blistering skin diseases, in which cleavage occurs between the dermis and the epidermis (right side of the diagram). Hemidesmosomal plaque proteins (BP230, plectin) interact with the transmembrane proteins BP180 and $\alpha 6 \beta 4$-integrin, which, in turn, are connected by way of laminin 332 to type VII collagen. Type VII collagen establishes a connection to dermal collagens. Proteins that have not been found to be targets of autoantibodies are not included in this diagram.
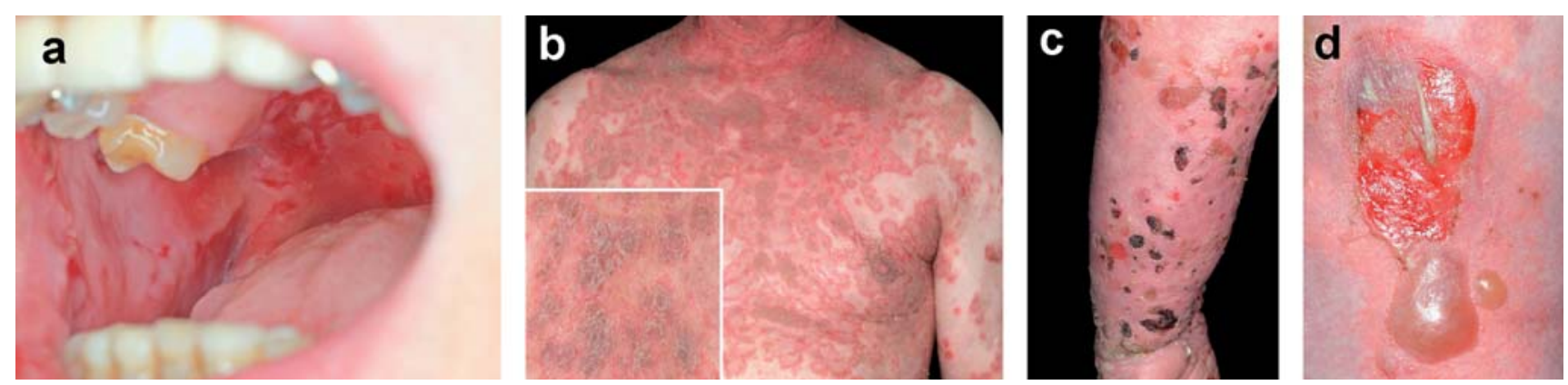

Figure 2: The clinical features of autoimmune blistering skin diseases.

a) Multiple buccal erosions in a woman with pemphigus vulgaris. Only the oral cavity is involved; the serum autoantibodies react exclusively with desmoglein 3.

b) Widespread erythematous plaques, urticarial erythema, and erosions with superficial scaling on the chest of a man with pemphigus foliaceus The autoantibodies are directed exclusively against desmoglein 1.

c,d) Tense blisters filled with serous fluid, erosions, and crusts on both erythematous and normal-appearing skin, on the arm of a woman with bullous pemphigoid. 
FIGURE 3
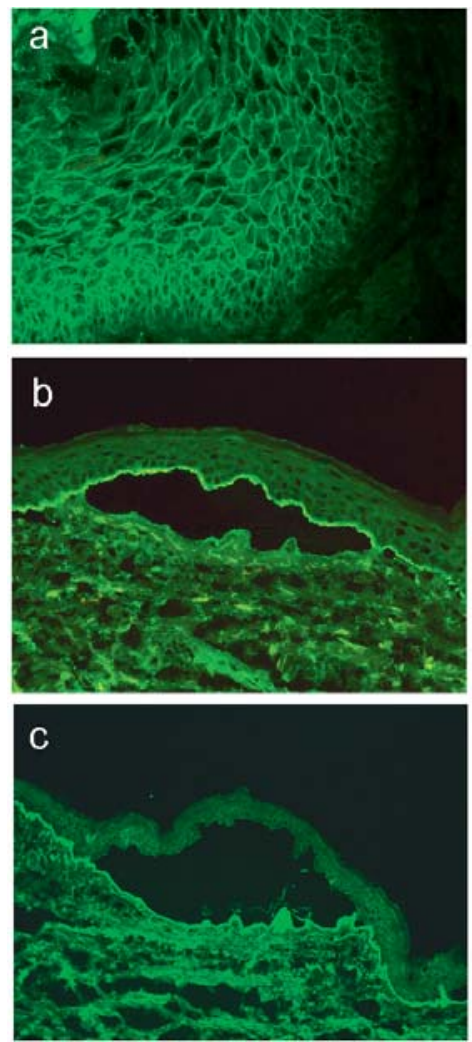

Mucous membrane pemphigoid

Laminin 332

Anti-p200 pemphigoid

Laminin $\gamma 1$

Epidermolysis bullosa acquisita Type VII collagen

Indirect immunofluorescence. Indirect immunofluorescence microscopy is used as a screening test for serum autoantibodies in autoimmune blistering skin diseases. The most sensitive substrates currently used include monkey esophagus for pemphigus vulgaris and pemphigus foliaceus (a) and human skin split with $1 \mathrm{M} \mathrm{NaCl}$ solution for pemphigoid diseases (b, c). Antibodies against type XVII collagen (BP180) and BP230 bind to the epidermal side of the artificial cleft (b), while antibodies against laminin 332 (previously known as laminin 5 or epiligrin), antibodies against the laminin $\gamma 1$ chain (p200 antigen), and antibodies against type VII collagen bind to its dermal side (c). The target antigens and the corresponding diseases are shown on the right side.

present in about $85 \%$ of patients with BP (e20, e21). Interestingly, most BP patients also develop $\operatorname{IgA}$ and IgE antibodies against BP180 (e22-e25). $60 \%$ to $70 \%$ of BP patients have circulating autoantibodies against BP230 (e26-e28), but the presence of these antibodies is much less specific than that of anti-BP-180 antibodies for the diagnosis of $\mathrm{BP}$ and is not correlated with disease activity (Table 1) (e26). A common observation in autoimmune blistering skin diseases is that a single patient can have autoantibodies recognizing multiple epitopes on a single target antigen, or on multiple target antigens; this is called intra- or intermolecular epitope spreading (e29).

In pemphigoid gestationis, immune reactivity is essentially limited to the NC16A domain of BP180 (e30-e33); on the other hand, in linear IgA dermatosis, the autoantibodies (which are characteristically of the IgA isotype) typically react with the soluble ectodomain of BP180 (Table 1) (e34, e35).
In mucous membrane pemphigoid, autoantibodies can be detected in only half of all patients with indirect IF microscopy on human split skin. These autoantibodies are mostly directed against BP180 (e36-e38); in about one-quarter of patients, antibodies against laminin 332 are found (e36, e39). The detection of the latter has a special significance, as $25 \%$ of patients who have them harbor a malignant neoplasm (Table 1) (3, e40).

The target antigen of the disease that was initially called anti-p200 pemphigoid (4) has recently been identified as the laminin- $\gamma 1$ chain (5). Patients with epidermolysis bullosa acquisita develop antibodies against type VII collagen (6), with the NC1 domain as the immune-dominant region (e41). Dermatitis herpetiformis is the cutaneous manifestation of celiac disease (sprue). In celiac disease, there are typically autoantibodies against endomysium and tissue transglutaminase; additional autoantibodies against epidermal transglutaminase are responsible for the cutaneous signs of the disease (Table 1) (7, e42).

\section{Serological tests over the course of the disease}

Autoantibodies against desmoglein 1 (in pemphigus foliaceus), desmoglein 3 (in pemphigus vulgaris), and the NC16A domain of BP180 (in BP) are correlated with disease activity $(2,8$, e43). The corresponding ELISAs are, therefore, suitable tests for monitoring disease activity over time and can be a useful aid in setting the optimal dose of the immunosuppressive medication(s) used to treat the disease.

\section{First-line treatments}

The treatment of autoimmune blistering skin diseases is problematic, because few prospective therapeutic trials have been performed in this field to date. The trials concerning BP and pemphigus have been summarized in Cochrane reviews $(9,10)$. The authors of the review on BP conclude that the application of topical steroids over a wide area is well-documented as a safe and effective treatment for this disease, and they state that the initial prednisolone dose should not exceed 0.75 $\mathrm{mg} / \mathrm{kg} / \mathrm{d}$ (9). For pemphigus vulgaris and pemphigus foliaceus, there have been too few therapeutic trials to enable any recommendation about treatment (10). No guidelines for the treatment of autoimmune blistering skin diseases have been issued to date in Germany; thus, our discussion here will be based on the guidelines of the British Association of Dermatologists $(11,12)$, as well as on an international consensus conference on the treatment of mucous membrane pemphigoid (13), a recent survey of 32 German dermatology departments (e44), and selected reviews (e45-e48)

Monotherapy of pemphigus with oral corticosteroids causes frequent side effects, including systemic infections $(70 \%$, of which $25 \%$ are lethal), diabetes mellitus $(45 \%)$, osteoporosis $(30 \%)$, thromboses $(15 \%)$, and gastrointestinal ulcers (15\%) (e49). Thus, in the treatment of pemphigus, systemic corticosteroids are given 
almost exclusively in combination with other immunosuppressive drugs such as azathioprine, mycophenolate mofetil, mycophenolate sodium, cyclophosphamide, and methotrexate (Table 2) (10, 11, e50, e51). Beissert et al., in a prospective, controlled study, found no significant difference between azathioprine $(2 \mathrm{mg} / \mathrm{kg} / \mathrm{d})$ and mycophenolate mofetil $(2 \mathrm{~g} / \mathrm{d})$ with respect to either efficacy or side effects when both drugs were given in combination with oral methylprednisolone (2 $\mathrm{mg} / \mathrm{kg} / \mathrm{d}$ ) (15). In contrast, Chams-Davatchi et al. found a corticosteroid-sparing effect of azathioprine $(2.5 \mathrm{mg} /$ $\mathrm{kg} / \mathrm{d})$ compared to mycophenolate mofetil $(2 \mathrm{~g} / \mathrm{d})$ both given in combination with oral prednisolone $(2 \mathrm{mg}$ / $\mathrm{kg} / \mathrm{d}$ ) (16). Recently, El Darouti et al. carried out a therapeutic trial on 64 patients with pemphigus vulgaris and reported a significantly better clinical effect from adjuvant pentoxyphylline in combination with sulfasalazine than from high-dose corticosteroids with cyclophosphamide (e53). The combination of pentoxyphylline and sulfasalazine exerts its effects by blocking TNF- $\alpha$ (e53). A recent controlled prospective trial involving 94 patients with pemphigus vulgaris who took prednisolone (1-2 $\mathrm{mg} / \mathrm{kg} / \mathrm{d}$ ) combined with either mycophenolate mofetil $(2-3 \mathrm{~g} / \mathrm{d})$ or placebo did not reveal any significant difference with respect to the primary endpoint (the percentage of patients who had no lesions and took no more than $10 \mathrm{mg}$ of prednisolone daily after one year of treatment). This trial did reveal a higher rate of adverse effects in the mycophenol atmofetil group, yet the rate of serious adverse events was lower in this group, while the response rate was higher, and the patients remained free of lesions or recurrences for a longer time (e54).

Subepidermal autoimmune blistering diseases can be treated with the immunosuppressant drugs that are used to treat pemphigus (see above), or else with dapsone or tetracycline; all of these agents are given in combination with topical or systemic corticosteroids (Table 2) $(9,12)$. The effects of dapsone and tetracycline in BP are now being studied in controlled prospective trials. Dapsone suppresses the local cutaneous immune response by inhibiting neutrophil function and chemotaxis. It is the drug of first choice in linear IgA dermatosis, dermatitis herpetiformis, and uncomplicated mucous membrane pemphigoid without ocular involvement (e55, e56). Moreover, high-potency topical corticosteroids have been shown to be just as effective as oral prednisolone $(0.5 \mathrm{mg} / \mathrm{kg} / \mathrm{d})$ in the treatment of BP, but with significantly fewer side effects $(29 \%$ versus $54 \%$ ) (14, e52). In mucous membrane pemphigoid with ocular involvement, adjuvant cyclophosphamide seems to be the most effective treatment (e57-e59).

\section{Treatment options for severe and intractable cases}

While BP, linear IgA dermatosis, pemphigoid gestationis, anti-laminin- $\gamma 1$ pemphigoid, and dermatitis herpetiformis usually respond well to treatment (Table 2), the treatment of pemphigus, mucous membrane pemphigoid, and epidermolysis bullosa acquisita is

\section{TABLE 2}

\section{First-line treatments for autoimmune blistering skin diseases ${ }^{* 1}$}

\begin{tabular}{|c|c|}
\hline Disease & Treatment \\
\hline \multicolumn{2}{|l|}{ Pemphigus } \\
\hline $\begin{array}{l}\text { Pemphigus vulgaris } \\
\text { Pemphigus foliaceus }\end{array}$ & $\begin{array}{l}\text { Prednisolone }\left(1.0-2.0 \mathrm{mg} / \mathrm{kg} / \mathrm{d}^{*}\right)^{* 3} \\
+ \text { azathioprine or mycophenolate mofetil } \\
\text { or cyclophosphamide }\end{array}$ \\
\hline Paraneoplastic pemphigus & $\begin{array}{l}\text { Treatment of malignancy + prednisolone } \\
\left(0.5-1.0 \mathrm{mg} / \mathrm{kg} / \mathrm{d}^{2}\right)+\text { cyclosporine or } \\
\text { cyclophosphamide or rituximab }\end{array}$ \\
\hline IgA pemphigus & $\begin{array}{l}\text { Dapsone or acitretin + prednisolone } \\
\left(0.5-1.0 \mathrm{mg} / \mathrm{kg} / \mathrm{d}^{2}\right)\end{array}$ \\
\hline \multicolumn{2}{|c|}{ Subepidermal autoimmune blistering skin diseases } \\
\hline Bullous pemphigoid & $\begin{array}{l}\text { Clobetasone propionate } 0.05 \% \text { cream } \\
(10-30 \mathrm{~g} / \mathrm{d})^{* 4}+\text { dapsone or doxycycline } \\
\text { or azathioprine or methotrexate }\end{array}$ \\
\hline Pemphigoid gestationis & $\begin{array}{l}\text { Topical class II or III corticosteroids } \\
+ \text { prednisolone }\left(0.25 \mathrm{mg} / \mathrm{kg} / \mathrm{d}^{+2}\right) \\
+ \text { + clemastine }\end{array}$ \\
\hline Linear $\lg A$ dermatosis & $\begin{array}{l}\text { Prednisolone }\left(0.25-0.5 \mathrm{mg} / \mathrm{kg} / \mathrm{d}^{*}\right)^{* 4} \\
+ \text { dapsone }\end{array}$ \\
\hline \multicolumn{2}{|l|}{ Mucous membrane pemphigoid } \\
\hline - without ocular involvement & $\begin{array}{l}\text { Prednisolone }\left(1.0 \mathrm{mg} / \mathrm{kg}^{*} \mathrm{~d}^{*}\right)^{* 3} \\
+ \text { dapsone or azathioprine or } \\
\text { mycophenolate mofetil }\end{array}$ \\
\hline - with ocular involvement & $\begin{array}{l}\text { Prednisolone }\left(1.5-2.0 \mathrm{mg} / \mathrm{kg} / \mathrm{d}^{*}\right)^{* 3} \\
+ \text { cyclophosphamide }\end{array}$ \\
\hline Lichen planus pemphigoides & $\begin{array}{l}\text { Prednisolone }\left(0.5 \mathrm{mg} / \mathrm{kg} / \mathrm{d}^{2}\right) \\
+ \text { acitretin + psoralen-UVA }\end{array}$ \\
\hline Anti-laminin $\gamma 1 /$ p200 pemphigoid & $\begin{array}{l}\text { Prednisolone }\left(0.25-0.5 \mathrm{mg} / \mathrm{kg} / \mathrm{d}^{*}\right)^{* 4} \\
+ \text { dapsone }\end{array}$ \\
\hline Epidermolysis bullosa acquisita & $\begin{array}{l}\text { Prednisolone }\left(1.0-2.0 \mathrm{mg} / \mathrm{kg} / \mathrm{d}^{*}\right)^{* 3} \\
+ \text { azathioprine or mycophenolate mofetil } \\
+ \text { colchicine }\end{array}$ \\
\hline Dermatitis herpetiformis & Gluten-free diet + dapsone \\
\hline
\end{tabular}

${ }^{* 1}$ In the absence of German treatment guidelines, this list is based on the guidelines of the British Association of Dermatologists $(11,12)$, an international consensus conference on the treatment of mucous membrane pemphigoid (13), a survey of German dermatological clinics (e44), and selected review articles, including two Cochrane reviews (9, 10, e45-e47).

${ }^{*}$ Initial dosage; the dose can be lowered depending on the clinical response. ${ }^{* 3}$ Alternatively, i.v. dexamethasone pulses (100 mg on each of three consecutive days) every three weeks, and at longer intervals thereafter

${ }^{*}$ It was shown in two controlled, prospective studies that clobetasone propionate $0.05 \%$ cream $(10-30 \mathrm{~g} / \mathrm{d})$ in a tapering dose is just as effective as prednisolone $(0.5 \mathrm{mg} / \mathrm{kg} / \mathrm{d})$, but with fewer side effects (14, e52)

${ }^{*}$ Not approved for use by pregnant women

often more difficult. Further therapeutic options for such cases include high-dose intravenous immunoglobulins, immunoadsorption, and rituximab.

\section{Intravenous immunoglobulins (IVIG)}

There have been reports of the use of IVIG in more than 200 patients with autoimmune blistering skin diseases, mainly pemphigus and mucous membrane pemphigoid, nearly all of whom showed clinical improvement (17, e60, e61). Recently, the efficacy of IVIG in pemphigus was unequivocally demonstrated in a prospective, multicenter, placebo-controlled trial 
(17). The most common dose of IVIG is 2 g per kilogram of body weight daily for five consecutive days; for patients with normal renal function, the entire dose can also be given over two days (e62, e63). The therapeutic benefit is enhanced by the simultaneous administration of immunosuppressive drugs (e61, e62, e64). IVIG is given every four weeks until all of the lesions are healed, and at lengthening intervals thereafter (e62). IVIG has fewer side effects than other adjuvant treatments: the infusion causes headache, fever, and shaking chills in about $25 \%$ of patients, and myalgia, arterial hypotension, tachycardia, and gastrointestinal symptoms in less than 5\% (e65). The German Dermatological Society recently issued guidelines on the indications, treatment protocol, duration of treatment, and evaluation of the therapeutic benefit of IVIG in the treatment of autoimmune blistering skin diseases (18).

\section{Immunoadsorption}

In immunoadsorption (IA), immunoglobulins are selectively removed from the blood. Autoantibodies have been shown to play a major role in the pathogenesis of pemphigus, BP, and epidermolysis bullosa acquisita ( 8 , 19, 20, e66-e68); thus, antibody removal is a rational treatment for these diseases. Unlike plasmapheresis, IA is not based on the substitution of fresh-frozen plasma or human albumin. IA can be performed either with disposable absorbers or with reusable systems. The latter are much more effective than the former, enabling a $75 \%$ reduction of autoantibodies in a single IA and a $95 \%$ reduction when IA is performed on three consecutive days (21, e69-e71).

Various protocols for the use of IA to treat autoimmune blistering skin diseases have been tested, always in combination with immunosuppressants (21, e69-e71). In all of these studies, the induction phase consisted of three or four IA treatments on consecutive days, usually with high-affinity adsorbers. All patients

\section{KEY MESSAGES}

- Autoimmune blistering skin diseases comprise about a dozen entities. They can be divided into pemphigus diseases and subepidermal bullous diseases. In pemphigus, the autoantibodies are directed against intercellular contact structures (desmosomes); in the pemphigoid diseases, they are directed against adhesion molecules of the basal membrane zone (hemidesmosomes).

- The incidence of autoimmune blistering skin diseases in Germany has doubled over the past 10 years to its current value of 25 new cases per million persons per year. Bullous pemphigoid is by far the most common of these diseases.

- The diagnostic gold standard is direct immunofluorescence microscopy of a perilesional biopsy. Today, however, the diagnosis can nearly always be made by serological testing in conjunction with a compatible clinical picture.

- Precise diagnosis is a prerequisite for accurate prognosis and effective treatment.

- No treatment guidelines are available in Germany to date. Expert recommendations have been issued on the use of immunoadsorption, rituximab, and IVIG for patients whose disease is severe or difficult to treat. benefited from the treatment, $20 \%$ of the patients with pemphigus had a complete remission (healing of all lesions and discontinuation of immunosuppressive drugs), and $50 \%$ of them had a clinical remission (healing of all lesions, while immunosuppressive drugs were still given). The main advantage of IA is its rapid clinical effect: it often results in the healing of all lesions within a few weeks $(21$, e69, e72). An expert panel recently issued detailed recommendations on the use of IA to treat autoimmune blistering diseases (22).

\section{Rituximab}

Treatment with rituximab removes CD20-positive B-lymphocytes from the circulation for three to nine months, and has been found to be effective against autoimmune blistering skin diseases - mainly pemphigus, which was the diagnosis in over $90 \%$ of the reported cases. In roughly $80 \%$ of the patients with pemphigus, all lesions were healed over the intermediate or long term (23, e73). Rituximab was almost always given as an adjuvant drug, i.e., in addition to another type of immunosuppressive treatment. The reported complications of rituximab treatment in patients with autoimmune blistering skin diseases include infections, deep venous thrombosis of the lower limbs, pulmonary embolism, long-term hypogammaglobulinemia, and neutropenia, with an overall mortality of 4\% (24, e73, e74). Rituximab can be given together with IA in order to combine the rapid improvement that is achievable with IA (21) with the excellent long-term results of rituximab; this has been done successfully in a few centers $(25$, e 75$)$. A consensus conference has established the indications, contraindications and dosage of rituximab treatment for autoimmune blistering skin diseases, as well as the variables that should be monitored over the course of treatment, and the criteria for discontinuing rituximab (25).

\section{Perspectives}

More people will need treatment for autoimmune blistering skin diseases in the future as the population ages and improved diagnostic testing makes diagnosis more likely. New standardized tests for all of these diseases are being developed. Specific and well-tolerated treatments are urgently needed; rituximab, infliximab, etanercept, leflunomide, doxycycline, omalizumab, and immunoadsorption are now being tested in controlled prospective trials (see www.clinicaltrial.gov).

\section{Conflict of interest statement \\ The authors state that they have received honoraria and payments of travel expenses from Roche AG and from Fresenius Medical Care. They also have a scientific cooperation with Eurimmun AG.}

Manuscript submitted on 19 November 2009;revised version accepted on 23 July 2010 .

Translated from the original German by Ethan Taub, M.D.

\section{REFERENCES}

1. Langan SM, Smeeth L, Hubbard R, Fleming KM, Smith CJ, West J: Bullous pemphigoid and pemphigus vulgaris-incidence and mortality in the UK: population based cohort study. BMJ 2008; 337: a180. 
2. Schmidt E, Dähnrich C, Rosemann A, et al.: Novel ELISA systems for antibodies to desmoglein 1 and 3: Correlation of disease activity with serum autoantibody levels in individual pemphigus patients. 2010; 19: 458-63.

3. Egan CA, Lazarova Z, Darling TN, Yee C, Cote T, Yancey KB: Antiepiligrin cicatricial pemphigoid and relative risk for cancer. Lancet 2001; 357: 1850-1.

4. Zillikens D, Kawahara Y, Ishiko A, et al.: A novel subepidermal blistering disease with autoantibodies to a $200-\mathrm{kDa}$ antigen of the basement membrane zone. J Invest Dermatol 1996; 106: 1333-8.

5. Dainichi T, Kurono S, Ohyama B, et al.: Anti-laminin gamma-1 pemphigoid. Proc Natl Acad Sci U S A 2009; 106: 2800-5.

6. Woodley DT, Briggaman RA, O'Keefe EJ, Inman A0, Queen LL, Gammon WR: Identification of the skin basement-membrane autoantigen in epidermolysis bullosa acquisita. N Engl J Med 1984; 310: 1007-13.

7. Sardy M, Karpati S, Merkl B, Paulsson M, Smyth N: Epidermal transglutaminase (TGase 3 ) is the autoantigen of dermatitis herpetiformis. J Exp Med 2002; 195: 747-57.

8. Schmidt E, Obe K, Brocker EB, Zillikens D: Serum levels of autoantibodies to BP180 correlate with disease activity in patients with bullous pemphigoid. Arch Dermatol 2000; 136: 174-8.

9. Khumalo N, Kirtschig G, Middleton P, Hollis S, Wojnarowska F, Murrell D: Interventions for bullous pemphigoid. Cochrane Database Syst Rev 2005; CD002292.

10. Martin LK, Werth V, Villanueva E, Segall J, Murrell DF: Interventions for pemphigus vulgaris and pemphigus foliaceus. Cochrane Database Syst Rev 2009; CD006263.

11. Harman KE, Albert S, Black MM: Guidelines for the management of pemphigus vulgaris. Br J Dermatol 2003; 149: 926-37.

12. Wojnarowska F, Kirtschig G, Highet AS, Venning VA, Khumalo NP: Guidelines for the management of bullous pemphigoid. $\mathrm{Br} \mathrm{J}$ Dermatol 2002; 147: 214-21.

13. Chan LS, Ahmed AR, Anhalt GJ, et al.: The first international consensus on mucous membrane pemphigoid: definition, diagnostic criteria, pathogenic factors, medical treatment, and prognostic indicators. Arch Dermatol 2002; 138: 370-9.

14. Joly P, Roujeau JC, Benichou J, et al.: A comparison of oral and topical corticosteroids in patients with bullous pemphigoid. N Engl $\mathrm{J}$ Med 2002; 346: 321-7.
15. Beissert S, Werfel T, Frieling U, et al.: A comparison of oral methylprednisolone plus azathioprine or mycophenolate mofetil for the treatment of pemphigus. Arch Dermatol 2006; 142: 1447-54.

16. Chams-Davatchi C, Esmaili N, Daneshpazhooh M, et al.: Randomized controlled open-label trial of four treatment regimens for pemphigus vulgaris. J Am Acad Dermatol 2007; 57: 622-8.

17. Amagai M, Ikeda S, Shimizu H, et al.: A randomized double-blind trial of intravenous immunoglobulin for pemphigus. J Am Acad Dermatol 2009; 60: 595-603.

18. Enk A, Fierlbeck G, French L, et al.: Use of high-dose immunoglobulins in dermatology. J Dtsch Dermatol Ges 2009; 7: 806-12.

19. Anhalt GJ, Labib RS, Voorhees JJ, Beals TF, Diaz LA: Induction of pemphigus in neonatal mice by passive transfer of IgG from patients with the disease. N Engl J Med 1982; 306: 1189-96.

20. Sitaru C, Mihai S, Otto C, et al.: Induction of dermal-epidermal separation in mice by passive transfer of antibodies specific to type VII collagen. J Clin Invest 2005; 115: 870-8.

21. Schmidt E, Klinker E, Opitz A, et al.: Protein A immunoadsorption: a novel and effective adjuvant treatment of severe pemphigus. $\mathrm{Br} \mathrm{J}$ Dermatol 2003; 148: 1222-9.

22. Zillikens D, Derfler K, Eming R, et al.: Recommendations for the use of immunoapheresis in the treatment of autoimmune bullous diseases. J Dtsch Dermatol Ges 2007; 5: 881-7.

23. Nagel A, Hertl M, Eming R: B-cell-directed therapy for inflammatory skin diseases. J Invest Dermatol 2009; 129: 289-301.

24. Schmidt E, Seitz CS, Benoit S, Brocker EB, Goebeler M: Rituximab in autoimmune bullous diseases: mixed responses and adverse effects. Br J Dermatol 2007; 156: 352-6.

25. Hertl M, Zillikens D, Borradori L, et al.: Recommendations for the use of rituximab (anti-CD20 antibody) in the treatment of autoimmune bullous skin diseases. J Dtsch Dermatol Ges 2008; 6: 366-73.

\section{Corresponding author:}

\section{Prof. Dr med. Dr. rer nat. Enno Schmidt}

Klinik für Dermatologie, Allergologie und Venerologie

Universität zu Lübeck

Ratzeburger Allee 160

23538 Lübeck, Germany

enno.schmidt@uk-sh.de

For eReferences please refer to: www.aerzteblatt-international.de/ref2311 


\title{
The Diagnosis and Treatment of Autoimmune Blistering Skin Diseases
}

\author{
Enno Schmidt, Detlef Zillikens
}

\section{eREFERENCES}

e1. Amagai M, Tsunoda K, Zillikens D, Nagai T, Nishikawa T: The clinical phenotype of pemphigus is defined by the anti-desmoglein autoantibody profile. J Am Acad Dermatol 1999; 40: 167-70.

e2. Anhalt GJ, Kim SC, Stanley JR, et al.: Paraneoplastic pemphigus. An autoimmune mucocutaneous disease associated with neoplasia. N Engl J Med 1990; 323: 1729-35.

e3. Anhalt GJ: Paraneoplastic pemphigus. J Investig Dermatol Symp Proc 2004; 9: 29-33.

e4. Zimmermann J, Bahmer F, Rose C, Zillikens D, Schmidt E: Clinical and immunopathological spectrum of paraneoplastic pemphigus. J Dtsch Dermatol Ges 2010; 8: 598-605.

e5. Kippes W, Schmidt E, Roth A, Rzany B, Brocker EB, Zillikens D: Immunopathologic changes in 115 patients with bullous pemphigoid. Hautarzt 1999; 50: 866-72.

e6. Hahn-Ristic K, Rzany B, Amagai M, Brocker EB, Zillikens D: Increased incidence of pemphigus vulgaris in southern Europeans living in Germany compared with native Germans. J Eur Acad Dermatol Venereol 2002; 16: 68-71.

e7. Bernard P, Vaillant L, Labeille B, et al.: Incidence and distribution of subepidermal autoimmune bullous skin diseases in three French regions. Bullous Diseases French Study Group. Arch Dermatol 1995; 131: 48-52.

e8. Zillikens D, Wever S, Roth A, Weidenthaler-Barth B, Hashimoto T, Brocker EB: Incidence of autoimmune subepidermal blistering dermatoses in a region of central Germany. Arch Dermatol 1995; 131: 957-8.

e9. Bertram F, Brocker EB, Zillikens D, Schmidt E: Prospective analysis of the incidence of autoimmune bullous disorders in Lower Franconia, Germany. J Dtsch Dermatol Ges 2009; 7: 434-40.

e10. Marazza G, Pham HC, Scharer L, et al.: Incidence of bullous pemphigoid and pemphigus in Switzerland: a 2-year prospective study. Br J Dermatol 2009; 161: 861-8.

e11. Jung M, Kippes W, Messer G, Zillikens D, Rzany B: Increased risk of bullous pemphigoid in male and very old patients: $A$ population-based study on incidence. J Am Acad Dermatol 1999; 41: $266-8$

e12. Beutner EH, Jordon RE: Demonstration of skin antibodies in sera of pemphigus vulgaris patients by indirect immunofluorescent staining. Proc Soc Exp Biol Med 1964; 117: 505-10.

e13. Kelly SE, Wojnarowska F: The use of chemically split tissue in the detection of circulating anti-basement membrane zone antibodies in bullous pemphigoid and cicatricial pemphigoid. Br J Dermatol 1988: 118: 31-40.

e14. Schmidt E, Zillikens D: Research in practice: diagnosis of subepidermal autoimmune bullous disorders. J Dtsch Dermatol Ges 2009; 7: 296-300.

e15. Amagai M, Komai A, Hashimoto T, et al.: Usefulness of enzymelinked immunosorbent assay using recombinant desmogleins 1 and 3 for serodiagnosis of pemphigus. Br J Dermatol 1999; 140: $351-7$. e16. Ishii K, Amagai M, Hall RP, et al.: Characterization of autoantibodies in pemphigus using antigen-specific enzymelinked immunosorbent assays with baculovirus-expressed recombinant desmogleins. J Immunol 1997; 159: 2010-7.

e17. Nagata Y, Karashima T, Watt FM, Salmhofer W, Kanzaki T, Hashimoto T: Paraneoplastic pemphigus sera react strongly with multiple epitopes on the various regions of envoplakin and periplakin, except for the c-terminal homologous domain of periplakin. J Invest Dermatol 2001; 116: 556-63.

e18. Zhang B, Zheng R, Wang J, Bu D, Zhu X: Epitopes in the linker subdomain region of envoplakin recognized by autoantibodies in paraneoplastic pemphigus patients. J Invest Dermatol 2006; 126 : 832-40.

e19. Probst C, Schlumberger W, Stocker W, et al.: Development of ELISA for the specific determination of autoantibodies against envoplakin and periplakin in paraneoplastic pemphigus. Clin Chim Acta 2009; 410: 13-8.

e20. Zillikens D, Mascaro JM, Rose PA, et al.: A highly sensitive enzyme-linked immunosorbent assay for the detection of circulating anti-BP180 autoantibodies in patients with bullous pemphigoid. J Invest Dermatol 1997; 109: 679-83.

e21. Sitaru C, Dahnrich C, Probst C, et al.: Enzyme-linked immunosorbent assay using multimers of the 16th non-collagenous domain of the BP180 antigen for sensitive and specific detection of pemphigoid autoantibodies. Exp Dermatol 2007; 16: 770-7.

e22. Kromminga A, Scheckenbach C, Georgi M, et al.: Patients with bullous pemphigoid and linear IgA disease show a dual IgA and $\lg$ G autoimmune response to BP180. J Autoimmun 2000; 15: 293-300.

e23. Mulyowa GK, Jaeger G, Kabakyenga J, Brocker EB, Zillikens D, Schmidt E: Autoimmune subepidermal blistering diseases in Uganda: correlation of autoantibody class with age of patients. Int J Dermatol 2006; 45: 1047-52.

e24. Iwata Y, Komura K, Kodera M, et al.: Correlation of IgE autoantibody to BP180 with a severe form of bullous pemphigoid. Arch Dermatol 2008; 144: 41-8.

e25. Dopp R, Schmidt E, Chimanovitch I, Leverkus M, Brocker EB, Zillikens D: IgG4 and IgE are the major immunoglobulins targeting the NC16A domain of BP180 in Bullous pemphigoid: serum levels of these immunoglobulins reflect disease activity. J Am Acad Dermatol 2000; 42: 577-83.

e26. Kromminga A, Sitaru C, Hagel C, Herzog S, Zillikens D: Development of an ELISA for the detection of autoantibodies to BP230. Clin Immunol 2004; 111: 146-52.

e27. Schmidt E, Kromminga A, Mimietz S, et al.: A highly sensitive and simple assay for the detection of circulating autoantibodies against full-length bullous pemphigoid antigen 180. J Autoimmun 2002; 18: 299-309.

e28. Yoshida M, Hamada T, Amagai M, et al.: Enzyme-linked immunosorbent assay using bacterial recombinant proteins of human BP230 as a diagnostic tool for bullous pemphigoid. J Dermatol Sci 2006; 41: 21-30. 
e29. Chan LS: Epitope spreading in paraneoplastic pemphigus: autoimmune induction in antibody-mediated blistering skin diseases. Arch Dermatol 2000; 136: 663-4.

e30. Sitaru C, Powell J, Messer G, Brocker EB, Wojnarowska F, Zillikens D: Immunoblotting and enzyme-linked immunosorbent assay for the diagnosis of pemphigoid gestationis. Obstet Gyneco 2004; 103: 757-63.

e31. Di Zenzo G, Calabresi V, Grosso F, Caproni M, Ruffelli M, Zambruno G: The intracellular and extracellular domains of BP180 antigen comprise novel epitopes targeted by pemphigoid gestationis autoantibodies. J Invest Dermatol 2007; 127: 864-73.

e32. Tamada Y, Yokochi K, Nitta Y, Ikeya T, Hara K, Owaribe K: Lichen planus pemphigoides: identification of $180 \mathrm{kd}$ hemidesmosome antigen. J Am Acad Dermatol 1995; 32: 883-7.

e33. Zillikens D, Caux F, Mascaro JM, et al.: Autoantibodies in lichen planus pemphigoides react with a novel epitope within the C-terminal NC16A domain of BP180. J Invest Dermatol 1999; 113: 117-21.

e34. Marinkovich MP, Taylor TB, Keene DR, Burgeson RE, Zone JJ: $L A D-1$, the linear IgA bullous dermatosis autoantigen, is a nove 120-kDa anchoring filament protein synthesized by epidermal cells. J Invest Dermatol 1996; 106: 734-8.

e35. Zillikens D, Herzele K, Georgi M, et al.: Autoantibodies in a subgroup of patients with linear IgA disease react with the NC16A domain of BP1801. J Invest Dermatol 1999; 113: 947-53.

e36. Schmidt E, Skrobek C, Kromminga A, et al.: Cicatricial pemphigoid: IgA and IgG autoantibodies target epitopes on both intraand extracellular domains of bullous pemphigoid antigen 180. $\mathrm{Br}$ J Dermatol 2001; 145: 778-83.

e37. Oyama N, Setterfield JF, Powell AM, et al.: Bullous pemphigoid antigen II (BP180) and its soluble extracellular domains are major autoantigens in mucous membrane pemphigoid: the pathogenic relevance to HLA class II alleles and disease severity. Br J Dermatol 2006; 154: 90-8.

e38. Bedane C, McMillan JR, Balding SD, et al.: Bullous pemphigoid and cicatricial pemphigoid autoantibodies react with ultrastructur ally separable epitopes on the BP180 ectodomain: evidence that BP180 spans the lamina lucida. J Invest Dermatol 1997; 108: 901-7.

e39. Lazarova Z, Hsu R, Yee C, Yancey KB: Antiepiligrin cicatricial pemphigoid represents an autoimmune response to subunits present in laminin 5 (alpha3beta3gamma2). Br J Dermatol 1998; 139: 791-7

e40. Leverkus M, Schmidt E, Lazarova Z, Brocker EB, Yancey KB, Zillikens D: Antiepiligrin cicatricial pemphigoid: an underdiagnosed entity within the spectrum of scarring autoimmune subepidermal bullous diseases? Arch Dermatol 1999; 135: 1091-8.

e41. Lapiere JC, Woodley DT, Parente MG, et al.: Epitope mapping of type VII collagen. Identification of discrete peptide sequences recognized by sera from patients with acquired epidermolysis bullosa. J Clin Invest 1993: 92: 1831-9.

e42. Rose C, Armbruster FP, Ruppert J, Igl BW, Zillikens D, Shimanovich I: Autoantibodies against epidermal transglutaminase are a sensitive diagnostic marker in patients with dermatitis herpetiformis on a normal or gluten-free diet. J Am Acad Dermatol 2009; 61: 39-43

e43. Harman KE, Seed PT, Gratian MJ, Bhogal BS, Challacombe SJ, Black MM: The severity of cutaneous and oral pemphigus is related to desmoglein 1 and 3 antibody levels. Br J Dermato 2001; 144: 775-80.

e44. Hofmann SC, Kautz O, Hertl M, Sticherling M, Zillikens D, Bruckner-Tuderman L: Results of a survey of German dermatologists on the therapeutic approaches to pemphigus and bullous pemphigoid. J Dtsch Dermatol Ges 2009; 7: 227-33.

e45. Goebeler M, Sitaru C, Zillikens D: Blistering autoimmune dermatoses (II): therapy. J Dtsch Dermatol Ges 2004; 2: 774-91.

e46. Mutasim DF: Management of autoimmune bullous diseases: pharmacology and therapeutics. J Am Acad Dermatol 2004; 51: 859-77; quiz 878-80. e47. Bystryn JC, Rudolph JL: Pemphigus. Lancet 2005; 366: 61-73.

e48. Kasperkiewicz M, Schmidt E: Current treatment of autoimmune blistering diseases. Curr Drug Discov Technol 2009; 6: 270-80.

e49. Rosenberg FR, Sanders S, Nelson CT: Pemphigus: a 20-year review of 107 patients treated with corticosteroids. Arch Dermatol 1976; 112: 962-70.

e50. Benoit S, Bröcker EB, Schmidt E: Current treatment of pemphigus. G Ital Dermatol Venereol 2007; 142: 363-80

e51. Kirtschig G, Murrell D, Wojnarowska F, Khumalo N: Interventions for mucous membrane pemphigoid/cicatricial pemphigoid and epidermolysis bullosa acquisita: a systematic literature review. Arch Dermatol 2002; 138: 380-4.

e52. Joly P, Roujeau JC, Benichou J, et al.: A comparison of two regimens of topical corticosteroids in the treatment of patients with bullous pemphigoid: a multicenter randomized study. J Invest Dermatol 2009; 129: 1681-7.

e53. El-Darouti M, Marzouk S, Abdel Hay R, et al.: The use of sulfasalazine and pentoxifylline (low-cost antitumour necrosis factor drugs) as adjuvant therapy for the treatment of pemphigus vulgaris: a comparative study. Br J Dermatol 2009; 161: 313-9.

e54. Beissert S, Mimouni D, Kanwar AJ, Solomons N, Kalia V, Anhalt GJ: Treating pemphigus vulgaris with prednisone and mycophenolate Mofetil: a multicenter, randomized, placebo-controlled trial. J Invest Dermatol 2010; 130: 2041-8.

e55. Cooper SM, Powell J, Wojnarowska F: Linear IgA disease successful treatment with erythromycin. Clin Exp Dermatol 2002; 27: $677-9$

e56. Schmidt E, Meyer-Ter-Vehn T, Zillikens D, Geerling G: Mucous membrane pemphigoid with ocular involvement. Part I: Clinical manifestations, pathogenesis and diagnosis. Ophthalmologe 2008; 105: 285-97.

e57. Meyer-ter-Vehn T, Schmidt E, Zillikens D, Geerling G: Mucous membrane pemphigoid with ocular involvement. Part II: therapy. Ophthalmologe 2008; 105: 405-19.

e58. Saw VP, Dart JK, Rauz S, et al.: Immunosuppressive therapy for ocular mucous membrane pemphigoid strategies and outcomes. Ophthalmology 2008; 115: 253-261.

e59. Foster CS: Cicatricial pemphigoid. Trans Am Ophthalmol Soc 1986; 84: 527-663.

e60. Ishii N, Hashimoto K, Zillikens D, Ludwig RJ: High-dose intravenous immunoglobulin (IVIG) therapy in autoimmune skin blistering diseases. Clin Rev Allergy Immunol 2010; 38: 186-95.

e61. Engineer L, Bhol KC, Ahmed AR: Analysis of current data on the use of intravenous immunoglobulins in management of pemphigus vulgaris. J Am Acad Dermatol 2000; 43: 1049-57.

e62. Ahmed AR: Intravenous immunoglobulin therapy in the treatment of patients with pemphigus vulgaris unresponsive to conventional immunosuppressive treatment. J Am Acad Dermatol 2001; 45: 679-90

e63. Herzog S, Schmidt E, Goebeler M, Brocker EB, Zillikens D: Serum levels of autoantibodies to desmoglein 3 in patients with therapyresistant pemphigus vulgaris successfully treated with adjuvant intravenous immunoglobulins. Acta Derm Venereol 2004; 84 $48-52$.

e64. Czernik A, Bystryn JC: Improvement of intravenous immunoglobulin therapy for bullous pemphigoid by adding immunosuppressive agents: marked improvement in depletion of circulating autoantibodies. Arch Dermatol 2008; 144: 658-61.

e65. Katz U, Achiron A, Sherer Y, Shoenfeld Y: Safety of intravenous immunoglobulin (IVIG) therapy. Autoimmun Rev 2007; 6: 257-9.

e66. Amagai M, Hashimoto T, Shimizu N, Nishikawa T: Absorption of pathogenic autoantibodies by the extracellular domain of pemphigus vulgaris antigen (Dsg3) produced by baculovirus. J Clin Invest 1994; 94: 59-67.

e67. Liu Z, Diaz LA, Troy JL, et al.: A passive transfer model of the organ-specific autoimmune disease, bullous pemphigoid, using antibodies generated against the hemidesmosomal antigen, BP180. J Clin Invest 1993; 92: 2480-8. 
e68. Sitaru C, Chiriac MT, Mihai S, et al.: Induction of complementfixing autoantibodies against type VII collagen results in subepidermal blistering in mice. J Immunol 2006; 177: 3461-8.

e69. Shimanovich I, Herzog S, Schmidt E, et al.: Improved protocol for treatment of pemphigus vulgaris with protein $\mathrm{A}$ immunoadsorption. Clin Exp Dermatol 2006; 31: 768-74.

e70. Lüftl M, Stauber A, Mainka A, Klingel R, Schuler G, Hertl M: Successful removal of pathogenic autoantibodies in pemphigus by immunoadsorption with a tryptophan-linked polyvinylalcohol adsorber. Br J Dermatol 2003; 149: 598-605.

e71. Schmidt E, Zillikens D: Immunoadsorption in dermatology. Arch Dermatol Res 2010; 302: 241-53.

e72. Eming R, Rech J, Barth S, et al.: Prolonged clinical remission of patients with severe pemphigus upon rapid removal of desmoglein-reactive autoantibodies by immunoadsorption. Dermatology 2006; 212: 177-87.

e73. Schmidt E, Goebeler M: CD20-directed therapy in autoimmune diseases involving the skin: role of rituximab. Expert Rev Dermatol 2008; 3: 259-278.

e74. Schmidt E, Goebeler M, Zillikens D: Rituximab in severe pemphigus. Ann N Y Acad Sci 2009; 1173: 683-91.

e75. Shimanovich I, Nitschke M, Rose C, Grabbe J, Zillikens D: Treatment of severe pemphigus with protein $A$ immunoadsorption, rituximab and intravenous immunoglobulins. Br J Dermatol 2008; 158: $382-8$. 